segment-peripheral iridectomy capsulehyaloidectomy and anterior vitrectomy. Case Rep Ophthalmol Med, 2012: p. 25-32.

3. Phạm Thị Thu Hà and Trân T Nguyêtt Thanh, Kết quả bước đâuu điêu trị glôcôm ác tính bằng phẫu thuật cắt dịch kính trước tái tạo tiền phòng. Tạp chí Nhãn khoa Việt Nam, 2014. 42: p. 3-11.

4. Spaeth GL and A. S, Comparison of the configuration of the human anterior chamber angle, as determined by the Spaeth gonioscopic grading system and ultrasound biomicroscopy. Trans Am Acad Ophthalmol Soc., 1995. 93: p. 337-347.

5. Xing Liu and $\mathbf{M}$. $\mathbf{L i}$, Phacoemulsification combined with posterior capsulorhexis and anterior vitrectomy in the management of malignant glaucoma in phakic eyes Acta Ophthalmologca, 2013. 91: p. 660-665.

6. Karolina Krix-Jachym and M. Rekas, Evaluation of the $E$ ffectiveness of Surgical Treatment of Malignant Glaucoma in Pseudophakic Eyes through Partial PPV with Establishment of Communication between the Anterior Chamber and the Vitreous Cavity. Journal ofOphthalmology, 2015: p. 21-27.

7. Juliane Matlach and J. Slobodda, Pars plana vitrectomy for malignant glaucoma in nonglaucomatous and in fitered glaucomatous eyes. Clinical ophthalmology, 2012. 6: p. 1959-1966.

\title{
ẢNH HƯởNG CỦA MộT SỐ YẾU TỐ ĐẾN SÃN SÀNG CHI TRẢ ĐỐI VỚI XÉT NGHIỆM SÀNG LỌC UNG THƯ ĐẠI TRỰC TRÀNG SỬ DỤNG XÉT NGHIỆM Tİ̀M MÁU ẨN TRONG PHÂN (FOBT) TẠI VIỆT NAM
}

\section{TÓM TẮT}

Mục tiêu: Xác định các yếu tố ảnh hưởng đến sẵn sàng chi trả (WTP) đối với xét nghiệm tìm máu ẩn trong phân (FOBT) để sàng lọc ung thư đại trực tràng tại Việt Nam. Phương pháp: Sử dụng mô hình hồi quy đa biến phân tích mối liên quan giữa WTP với các biến số độc lập (nhân khẩu - xã hội học, yếu tố nguy cơ của ung thư đại trực tràng và kiến thức-thái độ về ung thư đại trực tràng) từ bộ số liệu thu thập trên 402 đối tượng 50-75 tuổi đến khám bệnh thông thường tại các phòng khám ngoại trú thuộc Trung tâm y tế quận Hoàn Kiếm từ tháng 1 đến tháng 3/2019. Kết quả và kết luận: Lựa chọn sẵn sàng chi trả đối với FOBT được chỉ ra là có liên quan có ý nghĩa thống kê với tình trạng làm việc, số thành viên hộ gia đình, lo lắng bản thân sẽ mắc ung thư đại trực trà̀ng, đánh giá bản thân có nguy cơ mắc ung thư đại trực tràng bằng hoăc cao hơn người khác, người thân trực hệ có ít nhất 1 yếu tố nguy cơ ung thư đại trực tràng, có bảo hiểm y tế. Khi hiệu chỉnh WTP theo các yếu tố liên quan thì trung bình và trung vị WTP ước tính là 373.780 đồng (95\%KTC: 326.680; 438.490) và 309.970 đồng (95\%KTC: 278.710; 349.520).

Tư khóa: Sẵn sàng chi trả, đo lường sự ưa thích lý thuyết, phương pháp lượng giá ngâuu nhiên phụ thuộc, yếu tố liên quan, FOBT

\section{SUMMARY \\ DRIVING FACTORS OF WILLINGNESS TO PAY FOR COLORECTAL CANCER SCREENING USING FECAL OCCULT BLOOD TEST (FOBT) IN VIETNAM}

*Trường Đại học Y tế Công Cônng

Chịu trách nhiệm chính: Nguyễn Quỳnh Anh

Email: nqa@huph.edu.vn

Ngày nhận bài: 8.3.2021

Ngày phản biên khoa học: 27.4.2021

Ngày duyệt bài: 7.5.2021

\section{Nguyễn Quỳnh Anh*, Nguyễn Thu Hà*}

Objective: To analyze the driving factors of willingness to pay (WTP) for Fecal Occult Blood Test (FOBT) for colorectal cancer screening in Vietnam. Method: Employing logistic regression to analyze associated factors of WTP. We used the data from a cross-sectional survey employing contigent valuation method with double-bounded question design to estimate willingness to pay for FOBT. Survey was conducted on 402 patients aged 50-75 years old who went to the outpatient clinics of Hoan Kiem District Medical Center from January to March 2019. Results and conclusion: The choice of WTP was shown to be significantly related to variables including current working status, number of household members, The concern about himself will get colorectal cancer, assessing himself as having the same or higher risk of colorectal cancer than others, his relatives have at least one risks for developing colorectal cancer, having health insurance. When adjusting the value of WTP for those related factors, the mean and median WTP are 373,780 VND (95\%CI: 326,680; 438,490) and 309,970 VND (95\%CI: 278,710; 349,520).

Keywords: Willingness to pay, stated preference, contigent valuation, WTP, CV, driving factors, FOBT

\section{I. ĐĂT VẤN ĐỀ}

Nhằm cung cấp các bằng chứng hữu ích để xây dựng chương trình sàng lọc ung thư đại trực tràng (UTĐTT) một cách hiệu quả, y văn trền thế giới đã khẳng định vai trò của nghiên cứu ước tính sẵn sàng chi trả (WTP, willingness-topay) trong xác định mức đông chi trả phù hợp khi người dân sử dụng dịch vụ để vừa có thể đảm bảo nguôn tài chính cho các cơ sở cung ứng dịch vụ nhưng đồng thời cũng đảm bảo ở mức đồng chi trả như vậy, tỷ lệ tiếp cận và sử dụng dịch vụ sàng lọc là tối ưu [1]. Bằng chứng tữ một nghiên cứu về WTP chuẩn mực cũng có 
thể giúp cho các nhà quản lý có thể thiết kễ được các chương trình sàng lọc hiệu quả.

Có nhiều phương pháp để đo lường sẵn sàng chi trả, chẳng hạn như theo phân loại của Breidert và cộng sự [2], đo lường WTP bao gồm 2 nhóm lớn là đo lường sự ưa thích thực tê (reveal preference) và lý thuyết (stated preference). Đo lường sự ưa thích lý thuyết lại bao gồm kỹ thuật điều tra trực tiếp (direct survey) như phương pháp lượng giá ngẫu nhiên phụ thuộc (Contigent Valuation); và điều tra gián tiếp (indirect survey) như phân tích kết hợp (Conjoint Analysis) hay thử nghiệm lựa chọn rời rạc (Discrete-Choice Experiment).

Tại Việt Nam, nghiên cứu của tác giả Nguyễn Thu Hà và Nguyễn Quỳnh Anh (2020) về Đánh giá mức sẵn sàng chi trả đối với một số can thiệp phát hiện sớm ung thư tại Việt Nam được thực hiện từ tháng 1 đến tháng $3 / 2019$, áp dụng phương pháp lượng giá ngẩu nhiên phụ thuộc (Contigent Valuation) để xác định mức WTP đối với các xét nghiệm sàng lọc UTĐTT (sử dụng FOBT và nội soi đại trực tràng). Nghiên cứu tiến hành thu thập số liệu sử dụng các câu hỏi CóKhông hai mức trên 402 đối tượng là người dân đến khám bệnh thông thường có độ tuổi từ 50-75 tuổi tại các phòng khám bệnh ngoại trú của Trung tâm y tế Quận Hoàn Kiếm. Trong bài báo này, chúng tôi tập trung đi sâu phân tích các yếu tố ảnh hưởng đến lựa chọn sẵn sàng chi trả (choice of WTP) của đối tượng đối với xét nghiệm FOBT để sàng lọc UTĐTT. Việc xác định các yếu tố tiên lượng lựa chọn và mức WTP có ý nghĩa quan trọng trong việc xây dựng các kế hoạch sàng lọc trong tương lai, cũng như xác định các mức đồng chi trả cho sàng lọc UTĐTT trong tương lai để đảm bảo tỷ lệ sử dụng dịch vụ là tối ưu.

\section{II. ĐỐI TƯợNG VÀ PHƯƠNG PHÁP NGHIÊN CỨU}

Tiến hành phân tích dựa trên bộ số liệu đo lường WTP của tác giả Nguyễn Thu Hà và Nguyễn Quỳnh Anh (2020)[3]. Nghiên cứu này được thực hiện với phương pháp nghiên cứu được mô tả cự thể trong các phần sau.

2.1. Thiết kế nghiên cứu cắt ngang, sử dụng phương pháp lượng giá ngẫu nhiên phụ thuộc (Contingent Valuation) để xác định mức WTP đối với các xét nghiệm sàng lọc UTĐTT (thông qua thực hiện xét nghiệm máu ẩn trong phân (FOBT) và nội soi ĐTT)

2.2. Đối tượng nghiên cứu: Khách hàng đến khám bệnh tại cơ sở y tế ban đầu trên đia bàn thành phố Hà Nội thỏa mãn các tiêu chuẩn lựa chọn sau: (i) Độ tuổi từ 50 đến 75 tuổi; (ii) Không phân biệt giới tính; (iii) Chưa từng tham gia sàng lọc UTĐTT; (iv) Đồng ý tham gia phỏng vấn và đủ khả năng nghe nói hiểu tiếng Việt, không mắc bênh tâm thần.

3.3. Thời gian thu thập số liệu: Từ tháng 1 đến tháng 3 năm 2019

3.4. Địa điểm thu thập số liệu: Các phòng khám thuộc Trung tâm y tế quận Hoàn Kiếm - là cơ sở chăm sóc sức khỏe ban đầu, để đảm bảo lựa chọn được khách hàng có tham gia sử dụng dịch vụ y tế nhưng chưa từng tham gia sàng lọc UTĐTT.

3.5. Cỡ mẫu và phương pháp chọn mẫu: Áp dụng phương pháp ước tính cõ mẫu của Robert C. Mitchell và Richard T Carson [4], thực tế thu thập được số liệu của 402 đối tượng.

3.6. Biến số nghiên cứu: bao gồm các nhóm biến số chính (i) Thông tin cá nhân bao gồm thông tin nhân khẩu-xã hội học, kiến thức và thái độ đối với sàng lọc UTĐTT, yếu tố nguy cơ của UTĐTT; (ii) Thông tin mô tả bối cảnh đưa ra quyêt định về mức WTP; (iii) Nhóm câu hỏi nhằm xác định mức độ WTP sử dụng câu hỏi Có - Không hai mức; (iv) Nhóm câu hỏi nhằm khẳng định lý do đối tượng trả lời theo các lựa chọn đã đưa ra.

3.7. Nhập liệu, quản lý số liệu: Tiến hành nhập vào phần mềm Epi Data 3.1, sau đó làm sạch và được xử lý bằng phần mềm $R$.

3.8. Phân tích số liệu: Sử dụng gói phân tích $\mathrm{DCchoice}$ của phần mềm $\mathrm{R}$ dành riêng cho nghiên cứu đo lường sẵn sàng chi trả sử dụng phương pháp lượng giá ngẫu nhiên phụ thuộc với thiết kế câu hỏi có/không nhiều mức để phẩn tích số liệu. Mô hình đa biến sử dụng phương pháp ước tính mức sẵn sàng chi trả tuyến tính (parametric approach) với phân bố giả định của mức sẵn sàng chi trả là log-logistic.

\section{KẾT QUẢ NGHIÊN CỨU}

\subsection{Thông tin chung về đối tượng}

Bảng 1 trình bày thông tin về đặc điểm nhân khẩu - xã hội học, thái độ đối với UTĐTT của đối tượng tham gia nghiên cứu.

Bảng 1: Một số đặc điểm của đôi tượng nghiên cứu

\begin{tabular}{|c|c|c|c|}
\hline & Nam (n=119) & Nữ (n=283) & Chung (n=402) \\
\hline Tuối: Trung bình (SD) & $61,6(6,75)$ & $61,0(6,75)$ & $61,2(6,75)$ \\
\hline \multicolumn{4}{|c|}{ Trình độ học vấn } \\
\hline Chưa tốt nghiệp tiếu học & $12(10,1 \%)$ & $21(7,4 \%)$ & $33(8,2 \%)$ \\
\hline
\end{tabular}


VIETNAM MEDICAL JOURNAL N01 - MAY - 2021

\begin{tabular}{|c|c|c|c|}
\hline Tốt nghiệp tiểu học & $21(17,6 \%)$ & $88(31,1 \%)$ & $109(27,1 \%)$ \\
\hline Tốt nghiệp THCS & $14(11,8 \%)$ & $21(7,4 \%)$ & $35(8,7 \%)$ \\
\hline Tốt nghiệp THPT & $34(28,6 \%)$ & $61(21,6 \%)$ & $95(23,6 \%)$ \\
\hline Có trình độ chuyên môn & $38(31,9 \%)$ & $92(32,5 \%)$ & $130(32,3 \%)$ \\
\hline \multicolumn{4}{|c|}{ Tình trạng kết hôn } \\
\hline Chưa kết hôn/góa & $2(1,7 \%)$ & $12(4,2 \%)$ & $14(3,5 \%)$ \\
\hline Đã kết hôn & $117(98,3 \%)$ & $271(95,8 \%)$ & $388(96,5 \%)$ \\
\hline \multicolumn{4}{|c|}{ Gia đình thuộc diện hộ nghèo và cận nghèo } \\
\hline Mức sống trung bình trở lên & $94(79,0 \%)$ & $222(78,4 \%)$ & $316(78,6 \%)$ \\
\hline Cận nghèo & $14(11,8 \%)$ & $23(8,1 \%)$ & $49(12,2 \%)$ \\
\hline Nghèo & $11(9,2 \%)$ & $38(13,4 \%)$ & $37(9,2 \%)$ \\
\hline \multicolumn{4}{|c|}{ Tình trạng thẻ bảo hiếm y tế } \\
\hline Không có BHYT & $9(7,6 \%)$ & $26(9,2 \%)$ & $35(8,7 \%)$ \\
\hline Có BHYT & $110(92,4 \%)$ & $257(90,8 \%)$ & $367(91,3 \%)$ \\
\hline \multicolumn{4}{|c|}{ Bản thân có ít nhất 1 vấn đề sức khỏe nguy cơ đối với UTĐTT } \\
\hline Không & $68(57,1 \%)$ & $211(74,6 \%)$ & $279(69,4 \%)$ \\
\hline Có & $51(42,9 \%)$ & $72(25,4 \%)$ & $123(30,6 \%)$ \\
\hline \multicolumn{4}{|c|}{ Người thân có ít nhất 1 vấn đề sức khỏe nguy cơ đối với UTĐTT } \\
\hline Không & $83(69,7 \%)$ & $213(75,3 \%)$ & $296(73,6 \%)$ \\
\hline Có & $36(30,3 \%)$ & $70(24,7 \%)$ & $106(26,4 \%)$ \\
\hline \multicolumn{4}{|c|}{ Lo lắng mình sẽ mằc UTĐTT } \\
\hline Không hề lo lắng & $57(47,9 \%)$ & $137(48,4 \%)$ & $194(48,3 \%)$ \\
\hline Có lo lắng một chút & $52(43,7 \%)$ & $123(43,5 \%)$ & $175(43,5 \%)$ \\
\hline Khá lo lắng & $9(7,6 \%)$ & $22(7,8 \%)$ & $31(7,7 \%)$ \\
\hline Cực kì lo lắng & $1(0,8 \%)$ & $1(0,4 \%)$ & $2(0,5 \%)$ \\
\hline \multicolumn{4}{|c|}{ Tự đánh giá về nguy cớ mắc UTĐTT } \\
\hline Thấp hơn mọi người & $30(25,2 \%)$ & $81(28,6 \%)$ & $111(27,6 \%)$ \\
\hline Như mọi người & $67(56,3 \%)$ & $152(53,7 \%)$ & $219(54,5 \%)$ \\
\hline Cao hơn mọi người & $10(8,4 \%)$ & $10(3,5 \%)$ & $20(5,0 \%)$ \\
\hline Không biết & $12(10,1 \%)$ & $40(14,1 \%)$ & $52(12,9 \%)$ \\
\hline \multicolumn{4}{|c|}{ Lý do lớn nhất khiến người dần không thực hiện sàng lọc sử dụng FOBT } \\
\hline Thiếu kiến thức & $52(43,7 \%)$ & $106(37,5 \%)$ & $158(39,3 \%)$ \\
\hline Thấy không vệ sinh & $5(4,2 \%)$ & $21(7,4 \%)$ & $26(6,5 \%)$ \\
\hline Sợ hãi & $15(12,6 \%)$ & $32(11,3 \%)$ & $47(11,7 \%)$ \\
\hline Rào cản về thời gian & $5(4,2 \%)$ & $6(2,1 \%)$ & $11(2,7 \%)$ \\
\hline Rào cản về chi phí & $17(14,3 \%)$ & $40(14,1 \%)$ & $57(14,2 \%)$ \\
\hline Không được khuyến cáo & $2(1,7 \%)$ & $3(1,1 \%)$ & $5(1,2 \%)$ \\
\hline Khác & $3(2,5 \%)$ & $9(3,2 \%)$ & $12(3,0 \%)$ \\
\hline Không trả lời & $20(16,8 \%)$ & $66(23,3 \%)$ & $86(21,4 \%)$ \\
\hline
\end{tabular}

\subsection{Yếu tố liên quan đến lựa chọn chi trả cho FOBT}

Bảng 2 trình bày kết quả phân tích của mô hình đa biên. Trong đó, lựa chọn sẵn sàng chi trả (choice of WTP) với FOBT được chỉ ra là có liên quan có ý nghĩa thống kê với các biến số bao gồm tình trạng đang làm việc hiện tại, số thành viên trong hộ gia đình, sự lo lắng bản thân sẽ mắc UTĐTT, đánh giá bản thân có nguy cơ mắc UTĐTT bằng hoặc cao hơn người khác, người thân trực hệ có ít nhất 1 yếu tố nguy cơ đối với UTĐTTं (như bệnh dạ dày, trĩ, bệnh tim mạch, trâm cảm, ung thư khác), có BHYT và mức chi trả được đưa ra. Dấu của giá trị hệ số cho thấy chiêu của mối liên quan nhưng không chỉ ra được mức độ của mối liên quan.

Bảng 2: Môi liên quan giữa mức sã̃n sàng chi trả cho xét nghiệm tìm máu ẩn trong phân FOBT và các biến số độc lập

\begin{tabular}{|c|c|c|c|c|c|}
\hline Các biến số & Hệ số & SD & $\mathbf{Z}$ & \multicolumn{2}{|c|}{ P } \\
\hline Hằng số & 14,141 & 2,280 & 6,203 & 0,000 & $* * *$ \\
\hline Tuối & $-0,004$ & 0,023 & $-0,193$ & 0,847 & \\
\hline
\end{tabular}


TẠP CHÍ Y HỌC VIỆT NAM TẬP 502 - THÁNG 5 - SỐ 1 - 2021

\begin{tabular}{|c|c|c|c|c|c|}
\hline Thu nhập & 0,001 & 0,000 & 7,802 & 0,000 & *** \\
\hline Giới & $-0,362$ & 0,295 & $-1,226$ & 0,220 & \\
\hline Đã kết hôn & $-0,291$ & 0,845 & $-0,345$ & 0,730 & \\
\hline Hiện tại đang làm việc & $-0,972$ & 0,369 & $-2,634$ & 0,008 & ** \\
\hline Trình độ học vấn & $-0,186$ & 0,100 & $-1,855$ & 0,064 & \\
\hline Số thành viên trong hộ gia đình & 0,224 & 0,084 & 2,648 & 0,008 & ** \\
\hline Số con & 0,044 & 0,131 & 0,335 & 0,738 & \\
\hline Là người kiếm tiền chính trong gia đình & $-0,031$ & 0,332 & $-0,094$ & 0,925 & \\
\hline Lo lắng mình sẽ mắc UT ĐTT & 1,745 & 0,347 & 5,026 & 0,000 & $* * *$ \\
\hline $\begin{array}{c}\text { Đánh giá bản thân có nguy cơ mắc UT } \\
\text { ĐTT bằng hoặc cao hơn }\end{array}$ & $-0,935$ & 0,395 & $-2,371$ & 0,018 & * \\
\hline Người thân có ít nhất 1 VĐSK nguy cơ & $-1,000$ & 0,354 & $-2,827$ & 0,005 & ** \\
\hline Có ít nhất 1 VĐSK nguy cơ & $-0,631$ & 0,332 & $-1,901$ & 0,057 & . \\
\hline Đã từng sàng lọc UT ĐTT & 0,451 & 0,288 & 1,566 & 0,117 & \\
\hline Ua thích nội soi ĐTT & 0,568 & 0,321 & 1,769 & 0,077 & \\
\hline Có bảo hiểm y tế & 1,095 & 0,469 & 2,335 & 0,020 & $*$ \\
\hline Đi khám bệnh cùng người nhà & $-0,171$ & 0,299 & $-0,573$ & 0,567 & \\
\hline Mức & $-3,021$ & 0,215 & $-14,024$ & 0,000 & $* * *$ \\
\hline
\end{tabular}

Ghi chú: Mô hình đa biến, sử dụng phương pháp tuyến tính với phân bố log-logistic. Phân tích sử dụng gói phẩn tích "DCchoice" trên nền tảng phần mềm $R$.

$\mathrm{N}=372 ; \mathrm{AIC}=685 ; \mathrm{BIC}=759 ; \mathrm{LL}=-323$; (a) biến đổi hàm logarit; *** mức ý nghĩa thống kê 0.001 ; ** mức ý nghĩa thống kê $0.01 ; *$ mức ý nghĩa thống kê 0.05

Bảng 3 giúp đưa ra một số ước tính về giá trị sẵn sàng chi trả đối với xét nghiệm tìm máu ẩn trong phân FOBT khi đối tương có các đặc điểm khác nhau. Trong đó, sau khi hiệu chỉnh với các yếu tố liên quan, ước tính giá trị trung bình WTP nói chung là 373.780 đồng (95\%KTC: 326.680 ; 438.490). Giá trị trung vị WTP là 309.970 đồng (95\%KTC: 278.710; 349.520).

Bảng 3: Ước tính mức sãn sàng chi trả đôi với FOBT sau khi hiệu chỉnh dựa trên các yếu tố liên quan

\begin{tabular}{|c|c|c|}
\hline 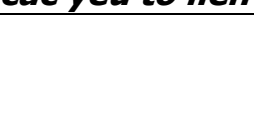 & $\begin{array}{c}\text { Trung bình } \\
\text { WTP } \\
(95 \% \mathrm{CI})\end{array}$ & $\begin{array}{l}\text { Trung vi } \\
\text { WTP } \\
(95 \% \mathrm{CI})\end{array}$ \\
\hline Chung & $\begin{array}{l}373.780 \\
(326.680 \\
438.490)\end{array}$ & $\begin{array}{l}309.970 \\
(278.710 ; \\
349.520)\end{array}$ \\
\hline Nữ & & \\
\hline \multicolumn{3}{|c|}{ Hiện đang làm việc } \\
\hline $\begin{array}{l}\text { Có lo lắng } \\
\text { mình sẽ mắc } \\
\text { UTĐTT }\end{array}$ & $\begin{array}{l}355.910 \\
(264.030 \\
490.960)\end{array}$ & $\begin{array}{l}295.150 \\
(223.230 ; \\
399.850)\end{array}$ \\
\hline $\begin{array}{l}\text { Không hề lo } \\
\text { lắng mình mắc } \\
\text { UTĐTT }\end{array}$ & $\begin{array}{c}199.790 \\
(145.390 ; \\
282.170) \\
\end{array}$ & $\begin{array}{c}165.680 \\
(121.380 \\
230.52) \\
\end{array}$ \\
\hline \multicolumn{3}{|c|}{ Hiện đang không làm việc } \\
\hline $\begin{array}{l}\text { Có lo lắng } \\
\text { mình sẽ mắc } \\
\text { UTĐTT }\end{array}$ & $\begin{array}{c}491.040 \\
(397.170 ; \\
640.130)\end{array}$ & $\begin{array}{c}407.210 \\
(333.550 ; \\
507.870)\end{array}$ \\
\hline $\begin{array}{l}\text { Không hề lo } \\
\text { lắng mình mắc }\end{array}$ & $\begin{array}{r}275.650 \\
(212.180 ;\end{array}$ & $\begin{array}{r}228.590 \\
(174.770 ;\end{array}$ \\
\hline
\end{tabular}

\begin{tabular}{|c|c|c|}
\hline UTĐTT & $362.960)$ & $298.490)$ \\
\hline Nam & & \\
\hline \multicolumn{3}{|c|}{ Hiện đang làm việc } \\
\hline Có lo lắng & 401.250 & 332.750 \\
mình sẽ mắc & $(289.510 ;$ & $(241.130 ;$ \\
UTĐTT & $563.420)$ & $453.230)$ \\
\hline Không hề lo & 225.240 & 186.790 \\
lắng mình mắc & $(159.600 ;$ & $(133.180 ;$ \\
UTĐTT & $319.280)$ & $260.960)$ \\
\hline \multicolumn{2}{|c|}{ Hiện đang không làm việc } \\
\hline Có lo lắng & 553.590 & 459.080 \\
mình sẽ mắc & $(419.700 ;$ & $(352.780 ;$ \\
UTĐTT & $752.770)$ & $605.6800)$ \\
\hline Không hề lo & 310.760 & 257.710 \\
lắng mình mắc & $(225.830 ;$ & $(184.910 ;$ \\
UTĐTT & $431.530)$ & $344.560)$ \\
\hline
\end{tabular}

\section{BÀN LUẬN}

Kết quả phân tích hồi quy logistic đa biến trong nghiên cứu này cũng cho thấy một số mối liên quan đến tỷ lệ từ chối chi trả chẳng hạn như đối tượng lo lắng mình sẽ mắc ung thư đại trực tràng và đánh giá bản thân có nguy cơ mắc ung thư ĐTT thấp hơn mọi người có xác suất từ chối chi trả cao hơn. Việc đối tượng lo lắng mình sẽ mắc ung thư đại trực tràng có xác suất từ chối chi trả cao hơn là tương đối đặc biệt khi cân nhắc với kết quả mối liên quan thuận chiều của yếu tố này lên mức WTP được ước tính dựa trên mô hình đa biến. Tuy nhiên, điều này cũng có thể lý giải được thông qua việc xem xét các lý do 
trả lời của đối tương từ chối xung quanh việc "sợ phát hiện ra bệnh".

Lựa chọn sẵn sàng chi trả (choice of WTP) được chỉ ra là có liên quan có ý nghĩa thống kê với các biến số bao gồm tình trạng đang làm việc hiện tại, số thành viên trong hộ gia đình, sự lo lắng bản thân sẽ mắc UTĐTT, đánh giá bản thân có nguy cơ mắc UTĐTT bằng hoặc cao hơn người khác, người thân trực hệ trong gia đình có ít nhất 1 yếu tố nguy cơ của UTĐTT (như bệnh dạ dày, trĩ, bệnh tim mạch, trầm cảm, ung thư khác), có thẻ bảo hiểm y tế và mức chi trả được đưa ra.

Kết quả được chỉ ra từ nghiên cứu này vừa có những điểm tương đồng và điểm khác biệt với một số nghiên cứu trên thế giới, chẳng hạn như một nghiên cứu về sẵn sàng chi trả đối với sàng lọc ung thư đại trực tràng, phổi và tụy của tác giả Sandra và cộng sự công bố năm 2016 tại Anh kết hợp thẻ chi trả kểt hợp với phương pháp đặt câu hỏi có/không (3 mức) dựa trên phần mềm máy tính. Trong nghiên cứu này, tuổi và thời gian đến cơ sở y tế không được chỉ ra là có liên quan đến giá WTP, ngược lại các yếu tố bao gồm thu nhập, trình độ học vấn và trước đó đã tham gia chẩn đoán ung thư đại trực tràng là các yếu tố ảnh hưởng đến giá trị WTP [1]. Hoặc trong tổng quan tài liệu công bố năm 2011 với 11 nghiên cứu ước tính WTP đối với các sàng lọc ung thư đại trực tràng cũng tóm tắt các yếu tố ảnh hưởng đến giá WTP bao gồm các yếu tố về dân số và kinh tế-xã hội của đối tượng như tuổi, giới, tôn giáo, thu nhập và trình độ học vấn; các yếu tố liên quan đến tình trang bênh, nhận thức về nguy cơ và tình trạng bệnh trong gia đình; và độ nhạy, độ đặc hiệu của các kỹ thuật chẩn đoán [5].

Việc sử dụng các biến số liên quan được chỉ ra từ nghiên cứu này có thể đóng vai trò quan trọng trong việc xây dựng các mô hình tiên lượng mức sẵn sàng chi trả của đối tượng. Tuy nhiên việc lựa chọn các biến số sử dụng trong mô hình tiên lượng cần phải được thực hiên một cách thận trọng nhằm đảm bảo tính chính xác cũng như tính thực tiễn của mô hình tiên lượng. Kết hợp với các cớ sở dữ liệu sẵn có, chẳng hạn như các thông tin đã được thu thập trong trang thông tin chung của toàn bộ đối tượng người dân tại Hà Nội đã tham gia sàng lọc trong chương trình sàng lọc ung thư đại trực tràng miễn phí đã diễn ra tại Hà Nội năm 2018 (bao gồm các thông tin cở bản như tuổi, giới tính, biểu hiện về tiêu hóa và yếu tố nguy cơ liên quan đến gia đình), việc xác định mức giá xét nghiệm FOBT và nội soi đại trực tràng để tối ưu hóa tỷ lệ người dân tham gia sàng lọc là hoàn toàn có thể thực hiện được.

Nhóm nghiên cứu cũng xem xét chi tiết các rào cản được đối tượng chỉ ra trong việc thực hiện xét nghiệm FOBT. Trong đó lý do phổ biến nhất được đưa ra không phải liên quan đến yếu tố mà là lý do liên quan đến kiến thức của người dân ("không nghĩ mình có bệnh" hay "thiếu hiểu biết thông tin khám sàng lọc", "không biết về phương pháp này có thể sàng lọc được" hay "chỉ khi nào có biểu hiện bệnh thì mới đi khám"). Lý do tiếp theo mới liển quan đến rào cản về chi phí với $14,2 \%$ ý kiến trả lời liên quan đến rào cản này, đặc biệt ở nhóm người cao tuổi không đủ điều kiện kinh tế hoặc kinh tế phụ thuộc vào con cái và liên quan đến "lo lắng chi phí xét nghiệm cao". Có một số lượng nhỏ (6,5\%) đối đượng đánh giá rào cản liên quan đến việc chi trả để thực hiện xét nghiệm FOBT là do người dân không sàng lọc sử dụng FOBT liên quan đến quy trình lấy phân có thể không vệ sinh ("nghĩ làm xét nghiệm phân liên quan tới giun sán" hay "ngại làm xét nghiệm phân vì sợ bẩn"). Một số nghiên cứu trên thể giới đã thực hiện về rào cản đối với người dân trong việc thực hiện xét nghiệm FOBT và nội soi đại trực tràng trong các chương trình sàng lọc ung thư đại trực tràng nói chung cũng chỉ ra một số yếu tố tương tự (chẳng hạn sợ hãi, quá trình chuẩn bị khiến đối tượng cảm thấy khó chịu, thiếu kiến thức, đau đớn và rào cản liên quan đến chi phí, các vấn đề khác đang hiện diện quan trọng hơn, thiếu khuyến cáo từ bác sỹ, không ưu tiên được thời gian để làm xét nghiệm [6]. Việc xem xét chi tiết các rào cản này cũng sẽ đóng vai trò quan trọng trong việc thiết kế được chương trình sàng lọc hiệu quả.

\section{KẾT LUẬN}

Lựa chọn sẵn sàng chi trả (choice of WTP) đối với FOBT được chỉ ra là có liên quan có ý nghĩa thống kê với các biến số bao gồm tình trạng đang làm việc hiện tại, số thành viên trong hộ gia đình, sự lo lắng bản thân sẽ mắc ung thư đại trực tràng, đánh giá bản thân có nguy cơ mắc ung thư đại trực tràng bằng hoặc cao hơn người khác, người thân trực hệ trong gia đình gặp phải ít nhất 1 vấn đề sức khỏe nguy cơ đối với ung thư đại trực tràng (như bệnh dạ dày, trĩ, bệnh tim mạch, trầm cảm, ung thư khác), có thẻ bảo hiểm y tế và mức chi trả được đưa ra.

\section{TÀI LIÊU THAM KHẢO}

1. Hollinghurst, S., et al., Using willingness-to-pay to establish patient preferences for cancer testing in primary care. BMC medical informatics and 
decision making, 2016. 16(1): p. 1-13.

2. Breidert, $C_{\text {., }} M$. Hahsler, and $T$. Reutterer, $A$ review of methods for measuring willingness-topay. Innovative Marketing, 2006. 2(4): p. 8-32.

3. Nguyễn Thu Hà and Nguyễn Quỳnh Anh, Báo cáo đề tài cấp cơ sở: Đánh giá mức sằn sàng chi trả đối với một số can thiêp phát hiện sớm ung thư tại Việt Nam - Nghiên cứu trường hợp đối với Ung thư đải trực tràng. 2020, Trường Đại học $Y$ tế Công cộng: Hà Nội, Việt Nam.
4. Mitchell, R.C., R.T. Carson, and R.T. Carson, Using surveys to value public goods: the contingent valuation method. 1989: Resources for the Future.

5. Lin, P.-J., et al., Willingness to pay for diagnostic technologies: a review of the contingent valuation literature. Value In Health, 2013. 16(5): p. 797-805.

6. Jones, R.M., et al., Patient-reported barriers to colorectal cancer screening: a mixed-methods analysis. American journal of preventive medicine, 2010. 38(5): p. 508-516.

\section{ĐÁNH GIÁ KẾT QUẢ THI LỰC VÀ Độ NHẠY CẢM TƯƠNG PHẢN TRÊN BỆNH NHÂN ĐĂT THỂ THƯY TINH NHÂN TẠO ACRYSOF RESTOR TORIC}

\section{TÓM TẮT}

Mục tiêu : Đánh giá kết quả thị lực và độ nhạy tương phản trên những bệnh nhân phẩu thuật phaco đă̆t TTT nhân tạo AcrySof ReStor Toric tại Bệnh viện Mắt trung ương. Đối tượng và phương pháp nghiên cứu: Nghiên cứu được tiến hành trên 52 mắt của 46 bênh nhân (gồm 24 nữ và 22 nam). Thời gian theo dõi là 1 tuần, 1 tháng, 3 tháng, 6 tháng, 1 năm bao gồm thị lực nhìn xa, nhìn gân, nhìn trung gian, khúc xạ tồn dư và độ nhạy cảm tương phản sau phâu thuật. Kết quả: Độ loạn thị giác mạc trung bình trước phẫu thuật là $1,94 \pm 0,53 \mathrm{D}$, độ loạn thị tồn dư sau phẫu thuật là $-0,32 \pm 0,47 \mathrm{D}$, ổn định sau 3 tháng. Sau mổ 12 tháng, $75 \%$ mắt có thị lực nhìn xa chưa chỉnh kính từ 20/25 trở lên. Thị lực trung gian, nhìn gần chưa chỉnh kính từ 20/40 trở lên tương ứng 88,46\% và $86,54 \%$. 96,15\% mắt không cần đeo kính nhìn xa, $90,38 \%$ không đeo kính khi nhìn trung gian và 86,53\% không đeo kính khi nhìn gần. 90,38\% độ nhay cảm tương phản bình thường. Kết luân: TTं nhẩn tạo AcrySof ReStor Toric có thể giúp bệnh nhân bị đục TTT kèm loạn thị giác mạc đều sau phẫu thuật giảm bớt phụ thuộc vào kính. Vấn đề chọn lựa bệnh nhân cũng như đo șinh trắc trước phẫu thuật là chìa khóa để có được phẫu thuật thành công.

Tư khóa: thể thủy tin nhân tạo AcrySof ReStor Toric , thị giác tương phản

\section{SUMMARY \\ VISUAL OUTCOMES AND CONTRAST VISION QUALITY AFTER ACRYSOF RESTOR TORIC IMPLANTATION}

Purpose: Assessment of VA and contrast vision outcome of AcrySof ReStor Toric implanted surgeries in VN Eye Hospital. Materials and Methods: Interventional Case Series Study, 52 eyes in 46 patients were implanted AcrySof ReStor Toric.

*Bệnh viện Mắt Trung Ương

Chịu trách nhiệm chính: Vũ Tuấn Anh

Email: vta.oph@gmail.com

Ngày nhận bài: 9.3.2021

Ngày phản biện khoa học: 26.4.2021

Ngày duyệt bài: 7.5.2021
Vũ Tuấn Anh*, Trần Thị Hoàng Nga*

Results: $75 \%$ have distant VA $\geq 20 / 25$, medium and near VA $\geq 20 / 40$ respectly $88,46 \%$ and $86,54 \%$. $90,38 \%$ of post-op eyes have excellent contrast vision. Conclusion: AcrySof ReStor Toric is best choice for astigmatism cataract eye. Patient selection and biometry were keys of success.

Tư khóa: AcrySof ReStor Toric lens, contrast vision

\section{I. ĐĂT VẤN ĐỀ}

Phẫu thuât phaco đặt TTT nhân tạo là phẫu thuật tiên tiến nhất để điều trị đục TTT hiện nay, giúp đem lại ánh sáng và nâng cao chất lượng cuộc sống cho người bênh, nhất là từ khi TTT nhân tao đa tiêu ra đời $[1],[2],[3]$. Tuy nhiên, để giải quyết vấn đề loạn thị của bệnh nhân phẫu thuật phaco, đặc biệt trên những bệnh nhân có nhu cầu đặt TTT nhân tạo đa tiêu lại là một trong những vấn đề trở ngại trong nhãn khoa. Để khắc phục tồn tại này, các phẩu thuâtt viên sẽ phải thực hiện thêm các thì phẫu thuật ngay trong quá trình mổ phaco như rạch giác mạc rìa hoăc bổ sung phẫu thuât khúc xạ bằng laser sau mổ phaco ${ }^{[4],[5]}$. Những kỹ thuật này có nhiều hạn chế như kéo dài thời gian điều trị, khả năng dự đoán kết quả kém, tình trạng khô mắt và các vấn đề phục hồi vết thương...

Thủy tinh thể nhân tạo AcrySof ReStor Toric (ART) ra đời đã bổ sung một giải pháp tốt để điều trị cho người bệnh đục TTT kèm loạn thị giác mạc đều mà người bệnh chỉ cần trải qua một lần phẫu thuât duy nhất [6].

TTT nhân tạo ART được xây dựng dựa trên nền tảng của TTT nhân tạo đa tiêu cự Acrysof ReSTOR và TTT nhân tạo điều chỉnh loạn thị Acrysof IQ Toric [6].

Chúng tôi tiến hành nghiên cứu này nhằm đánh giá kết quả thị lực và độ nhay cảm tương phản sau phẫu thuật đặt TTT nhẩn tạo ART ở bệnh nhân đục TTT kèm loạn thị giác mạc đều. 